\title{
Effect of Applied Voltage on the Microstructure and Bioactivity of MAO Film on Ti Substrate
}

\author{
Ma Fengcang ${ }^{1, *}$, Liu Ping ${ }^{1}$, Li Wei ${ }^{1}$, Liu Xinkuan ${ }^{1}$, Chen Xiaohong ${ }^{1}$, \\ He Daihua ${ }^{1}$, Wang Liqiang ${ }^{2}$ and Geng Fang ${ }^{3}$ \\ ${ }^{1}$ School of Materials Science and Engineering, University of Shanghai for Science and Technology, Shanghai 200093, China \\ ${ }^{2}$ State Key Lab Metal Matrix Composites, Shanghai Jiaotong University, Shanghai 200240, China \\ ${ }^{3}$ Shanghai MicroPort Orthopedics Company with Limited Liability, Shanghai 201318, China
}

\begin{abstract}
Various MAO films were prepared on Ti-6Al-4V substrate at voltages from 300 to $550 \mathrm{~V}$ in an electrolyte containing $0.18 \mathrm{M}$ calcium acetate and $0.1 \mathrm{M}$ sodium dihydrogen phosphate using an AC mode. Microstructures and phases of the MAO films were investigated by SEM with EDS and XRD. Bioactivity was examined using an apatite formation test in a simulated body fluid. The results show that the applied voltage has a significant influence on the microstructure and composition. With the increase in the applied voltage the sizes of micropores increase, and $\mathrm{Ca} \mathrm{P}$ contents and $\mathrm{Ca} / \mathrm{P}$ ratio in the $\mathrm{MAO}$ film increase too. And the $\mathrm{Ca} \mathrm{P}$ contents in this work are increased obviously compared to DC MAO mode. The MAO films contain rutile, anatase and amorphous calcium phosphate, and higher voltage is favorable to form rutile phase. The results of the apatite formation test show that the AC MAO films exhibit higher ability to form apatite than DC mode. It is suggested that the AC MAO mode is more effective to incorporate calcium and phosphorous in the oxide layer than DC mode because higher applied voltages can be applied in it, and the AC MAO film present a better performance in the formation of calcium phosphate which may be result from a more effective release of CaP from MAO film into SBF. [doi:10.2320/matertrans.M2013004]
\end{abstract}

(Received January 7, 2013; Accepted June 10, 2013; Published July 19, 2013)

Keywords: microarc oxidation, microstructure, bioactivity, apatite formation

\section{Introduction}

Due to its excellent mechanical properties, biocompatibility, manufacturability, and osseointegration behavior, titanium metal and its alloys have become an excellent material for dental and orthopedic implants. ${ }^{1-3)}$ However, titanium is a bioinert material that neither chemically connects to bone nor actively induces bone growth. Various surface modifications on titanium implants have been carried out to improve its bioactivity.

Among the surface modification methods used to improve Ti alloys bioactivity, anodic oxidation has attracted considerable attention on account of its many advantages, which include its capability to produce porous titanium oxide films through dielectric breakdown known as microarc oxidation (MAO), improved adhesion to the substrate metal, and the ability to change the composition of the oxide film depending on the type of electrolyte used. ${ }^{4,5)}$ Some reports have shown that the wear resistance, chemical stability, and biocompatibility of the metals can be significantly improved after a MAO treatment. Previous researches also indicated that MAO $\mathrm{TiO}_{2}$-based film containing $\mathrm{Ca}$ and $\mathrm{P}$ can be prepared by treating the $\mathrm{Ti}$ alloy in an electrolyte containing $\mathrm{Ca}$ and $\mathrm{P}$, and the addition of $\mathrm{Ca}$ and $\mathrm{P}$ in the MAO film improved the bioactivity. ${ }^{6,7)}$

Some researchers reported that the applied voltage had important influences on the microstructure and $\mathrm{Ca}$ and $\mathrm{P}$ concentration of the MAO films, and higher voltage is beneficial to obtain higher content of $\mathrm{Ca}$ and $\mathrm{P}$ film. ${ }^{8,9)}$ But conventional anodic oxidation treatments have been accomplished using an electric power supply in direct-current mode (DC) at lower voltages. Recently, an alternating-current (AC)-type MAO method was introduced to modify the

*Corresponding author, E-mail: mafengcang@163.com surface of dental or orthopedic implants owing to its high wear and corrosion resistance, porous topology and good adhesion to $\mathrm{Ti}$ metal. The $\mathrm{AC}$ mode with higher voltages supply may be a better choice for MAO treatment. It provides higher local discharge intensity than DC mode, which facilitates the formation of the large thickness film and the change of the MAO composition. ${ }^{10)}$ Ho-Jun Song et al. ${ }^{11)}$ carried out MAO treatments to fabricate $\mathrm{Ti}$ oxide film containing $\mathrm{CaP}$ with the $\mathrm{AC}$ mode at 150 or $175 \mathrm{~V}$, which shows that the characteristics of the oxide films fabricated using the AC-type MAO depend on the voltage and frequency.

In this study, the MAO films containing calcium and phosphorus were fabricated on titanium metal using the AC mode at higher voltages from 300 to $550 \mathrm{~V}$. Micromorphology, crystalline structure and the $\mathrm{Ca}$ and $\mathrm{P}$ content of the films were evaluated. In addition, the bioactivity of the MAO films prepared at various voltages was examined using the formation of apatite test in an SBF.

\section{Experiment}

Commercial medical Ti-6Al-4V plates (sample size: $15 \times 30 \times 1.5 \mathrm{~mm}$ ) were used in the study. Samples were abraded using $\mathrm{SiC}$ sandpaper no. 800, then rinsed using a mixture of hydrofluoric and nitric acids $\left(1: 3 \mathrm{HF} / \mathrm{HNO}_{3}\right)$, and finally washed with acetone in an ultrasonic cleaner. MAO was performed with a rectangular pulse power supply. Electrolytes were prepared by dissolution of calcium acetate $0.18 \mathrm{M}$ and sodium dihydrogen phosphate $0.1 \mathrm{M}$ in deionized water. The electrolyte cell consisted of a stainless steel container. Schematic diagram and parameters representation of microarc oxidation process used in this experiment are presented in Fig. 1. The frequency of the rectangular pulse used in the MAO was $400 \mathrm{~Hz}\left(t_{1} / t\right.$ was $20 \%$ and $t_{2} / t$ was 


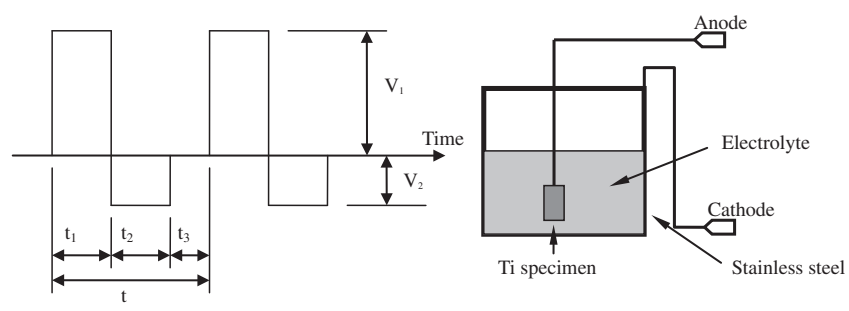

Fig. 1 Schematic diagram and parameters representation of microarc oxidation process.

$20 \%$ ). Because the MAO film on Ti substrate was formed only when Ti was applied a positive voltage, positive voltage play a more important role during MAO process than negative voltage. The applied voltage $\left(V_{1}\right)$ in this work was $300,350,400,450,500$ and $550 \mathrm{~V}$, respectively, and $V_{2}$ was fixed at $20 \mathrm{~V}$. The temperature of the electrolyte was kept at 40 to $60^{\circ} \mathrm{C}$ by a cooling system. The MAO processes were performed for $10 \mathrm{~min}$. After MAO treated, the samples were washed with deionized water (dipping into deionized water 5 times).

The oxide film microstructures were observed by scanning electron microscopy (SEM: FEI Quatan 450, Japan) equipped with EDS, which was used to also analyze the composition of the samples. The surface phases of the films were analyzed by X-ray diffraction (XRD: D8-Advanced; Bruker, Germany) using $\mathrm{Cu} \mathrm{K} \alpha$ radiation at a scanning speed of $4.0^{\circ} / \mathrm{min}$ and using a scanning range $(2 \theta)$ of 20 to $65^{\circ}$. The bioactivity of the films was examined using the formation of apatite in simulated body fluid (SBF). The SBF was prepared by dissolving reagent-grade $\mathrm{NaCl}, \mathrm{NaHCO}_{3}, \mathrm{KCl}, \mathrm{K}_{2} \mathrm{HPO}_{4}$. $3 \mathrm{H}_{2} \mathrm{O}, \mathrm{MgCl}_{2}, \mathrm{CaCl}_{2}$ and $\mathrm{Na}_{2} \mathrm{SO}_{4}$ into deionized water and buffering at $\mathrm{pH} 7.40$ with tris (hydroxymethyl) aminomethane $\left(\left(\mathrm{CH}_{2} \mathrm{OH}\right)_{3} \mathrm{CNH}_{2}\right)$ and $1.0 \mathrm{M} \mathrm{HCl}$. In this test, the MAO samples were soaked in $50 \mathrm{ml}$ of SBF at $37^{\circ} \mathrm{C}$ for 7 days, then were gently washed with deionized water and dried at $25^{\circ} \mathrm{C}$. Ca and $\mathrm{P}$ concentrations of the SBF immersion of the MAO coatings for $12,24,48,72,96 \mathrm{~h}$ were measured by inductively coupled plasma optical emission spectroscopy (ICP-OES; Optima 5300DV, Perkin-Elmer, America). The micrograph of the apatite formed on the MAO films was observed by scanning electron microscopy.

\section{Results and Discussion}

\subsection{Phases identification and MAO film thickness}

Figure 2 shows the XRD patterns of the MAO film performed at 350,450 and $550 \mathrm{~V}$. As shown in Fig. 2, the film consists of rutile $\mathrm{TiO}_{2}$ and anatase $\mathrm{TiO}_{2}$ besides Ti phase, and no additional crystal phases formed by $\mathrm{Ca}$ or $\mathrm{P}$ can be identified in this work. This result is in accordance with previous reports which show that $\mathrm{Ca}$ and $\mathrm{P}$ in the MAO film is an amorphous phase. ${ }^{12,13)}$ It also can be seen from Fig. 2 that the peak of rutile become stronger in the patterns when the applied voltage is increased from 350 to $550 \mathrm{~V}$, which can be seen from the peak of rutile at $26.2^{\circ}$ compared to that of anatase at $27.5^{\circ}$. This result indicates that high voltage applied in MAO is favorable to form rutile phase. On the other hand, the peaks of rutile are more obvious in the

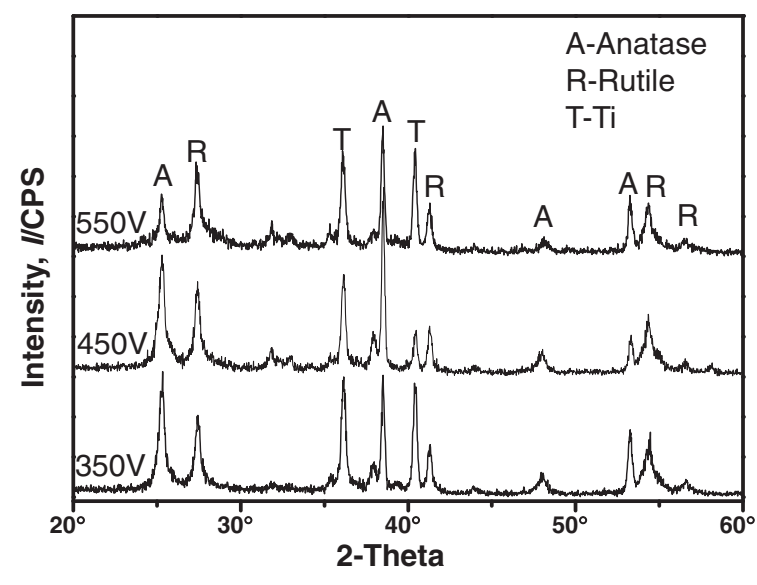

Fig. 2 X-ray diffraction patterns of the MAO films.

patterns of AC MAO film presented in Fig. 2 than those of DC MAO film, ${ }^{14)}$ which may be resulted from a higher voltage used in AC mode than DC mode.

The thicknesses of the oxide films in this work were examined by SEM. The thickness of the prepared MAO films is about $5 \mu \mathrm{m}(300 \mathrm{~V}), 9 \mu \mathrm{m}(350 \mathrm{~V}), 12 \mu \mathrm{m}(400 \mathrm{~V}), 15 \mu \mathrm{m}$ $(450 \mathrm{~V}), 17 \mu \mathrm{m}(500 \mathrm{~V}), 19 \mu \mathrm{m}(550 \mathrm{~V})$, respectively. These results show that with the increase in the applied voltage the thickness of the oxide film increases. In general, the growth rate and maximum thickness of the oxide film are dependent on the applied voltage, and they increase with the applied voltage.

\subsection{Effects of applied voltage on morphology and composition of the MAO films}

\subsubsection{Surface morphology}

The surface morphologies of the MAO films formed at various voltages $(300-550 \mathrm{~V})$ are shown in Fig. 3. The MAO films show a porous structure, which is formed during microarc discharge process. The MAO films are distributed at regular intervals at low applied voltages $(350 \mathrm{~V})$. Above $450 \mathrm{~V}$, the surfaces of the MAO films become rough and irregular. The average size of micro-pores on the MAO film increases with increasing the applied voltage. Moreover, the uniformity extent of the micro-pore size increases. The results indicate that the applied voltage has a significant effect on the surface morphology of the MAO film, especially for the size of micro-pores used the present electrolyte.

\subsection{2 $\mathrm{Ca}$ and $\mathrm{P}$ contents and $\mathrm{Ca} / \mathrm{P}$ of $\mathrm{MAO}$ film}

The $\mathrm{CaP}$ contents and $\mathrm{Ca} / \mathrm{P}$ ratios of the $\mathrm{MAO}$ films formed at various voltages $(300-550 \mathrm{~V})$ are shown in Fig. 4. The results reveal that the $\mathrm{Ca}$ content and $\mathrm{Ca} / \mathrm{P}$ ratio of the MAO films increases with increasing the applied voltage, which indicates that the $\mathrm{Ca}, \mathrm{P}$ contents and $\mathrm{Ca} / \mathrm{P}$ ratios of the MAO films can be controlled by the voltage applied in MAO process. Above $400 \mathrm{~V}$, a slow increase in $\mathrm{P}$ content was observed, but the $\mathrm{Ca}$ content and $\mathrm{Ca} / \mathrm{P}$ ratio increase continuously, which shows that high voltage is favorable to increase the content of $\mathrm{Ca}$ and $\mathrm{P}$ in MAO film, especially to increase the content of $\mathrm{Ca}$. The highest $\mathrm{CaP}$ and $\mathrm{Ca}$ content is about 27 at $\%, 18$ at\%, respectively. L. Fu et al. ${ }^{14)}$ show that the $\mathrm{CaP}$ and $\mathrm{Ca}$ content of the MAO film prepared by DC mode are not more than 15 and 10 at\%. In this work, the 

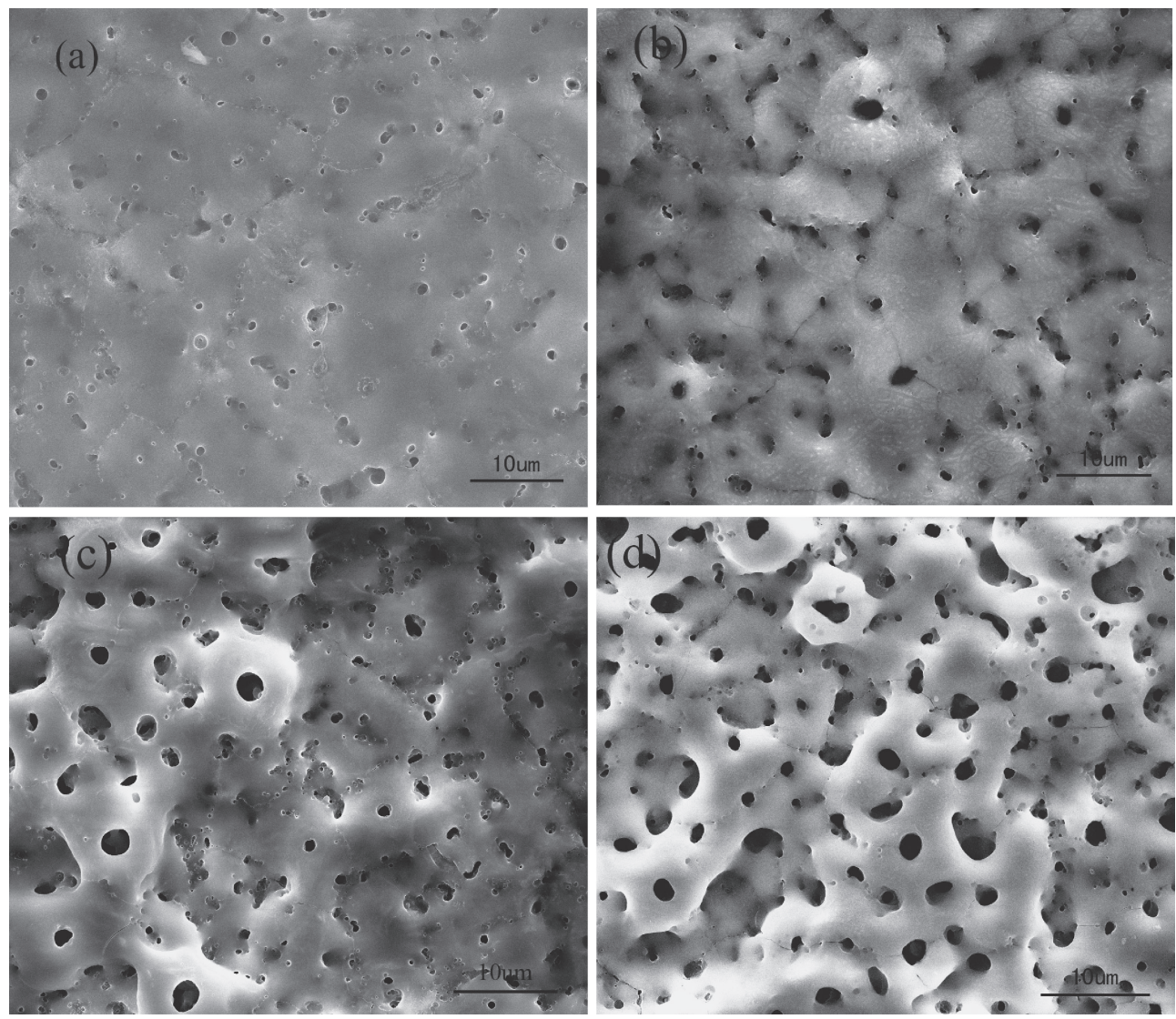

Fig. 3 SEM of the MAO films surface prepared at various applied voltages; (a) $300 \mathrm{~V}$, (b) $350 \mathrm{~V}$, (c) $450 \mathrm{~V}$, (d) $550 \mathrm{~V}$.

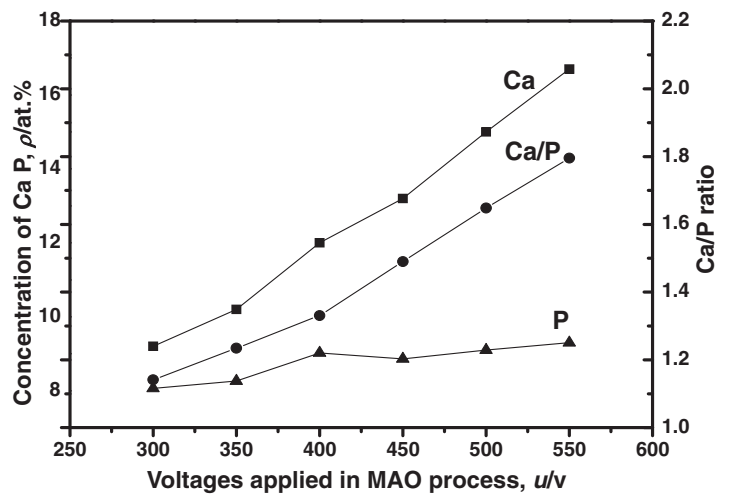

Fig. 4 Changes in the $\mathrm{Ca}, \mathrm{P}$ content and $\mathrm{Ca} / \mathrm{P}$ ratio of the $\mathrm{MAO}$ film as a function of the applied voltage during $\mathrm{MAO}$ process.

$\mathrm{Ca} / \mathrm{P}$ ratio of the MAO film prepared at $500 \mathrm{~V}$ is 1.63 , which is the nearest one to that of human bone (1.67). Because higher voltage can be applied in AC mode MAO, AC mode is more helpful to prepare the $\mathrm{MAO}$ films with high $\mathrm{CaP}$ contents than DC mode.

On the other hand, the increase of the $\mathrm{Ca}$ and $\mathrm{P}$ contents could lead to the formation of a large quantity of amorphous $\mathrm{Ca}$ and $\mathrm{P}$ phase. T. Nakamura et al. ${ }^{15)}$ has believed that amorphous $\mathrm{Ca}$ and $\mathrm{P}$ phase facilitates the initial fixation of porous materials due to their excellent osteoconductive property. Thus, the present results may provide a variety of choices due to all the MAO films containing amorphous $\mathrm{Ca}$ and $\mathrm{P}$ phase. Furthermore, the $\mathrm{Ca}$ and $\mathrm{P}$ content could
Table 1 Ion concentrations of the SBF used in this work and those in human blood plasma.

\begin{tabular}{llc}
\hline \multirow{2}{*}{ Ion } & \multicolumn{2}{c}{ Concentration $(c / \mathrm{mM})$} \\
\cline { 2 - 3 } & $\mathrm{SBF}$ & Blood plasma \\
\hline $\mathrm{Na}^{+}$ & 142.0 & 142.0 \\
$\mathrm{~K}^{+}$ & 5.0 & 5.0 \\
$\mathrm{Mg}^{2+}$ & 1.5 & 1.5 \\
$\mathrm{Ca}^{+}$ & 2.5 & 2.5 \\
$\mathrm{Cl}^{-}$ & 147.8 & 103.8 \\
$\mathrm{HCO}_{3}{ }^{2-}$ & 4.2 & 27 \\
$\mathrm{HPO}_{4}{ }^{2-}$ & 1.0 & 1.0 \\
$\mathrm{SO}_{4}{ }^{2-}$ & 0.5 & 0.5 \\
\hline
\end{tabular}

influence biological performance of the MAO film, which is presented in the following.

\section{3 $\mathrm{Ca}$ and $\mathrm{P}$ release and apatite formation of the MAO films in SBF}

The bioactivity of the films was examined using the apatite formation test in the SBF. The ionic concentrations of the $\mathrm{SBF}$ and that of the human blood plasma are presented in Table 1. The $\mathrm{Ca}$ and $\mathrm{P}$ concentrations of the SBF after immersed for various time are presented in Fig. 5. As presented in Fig. 5, the concentrations of $\mathrm{Ca}$ and $\mathrm{P}$ increase obviously in the first $72 \mathrm{~h}$ during immersion process. After $72 \mathrm{~h}$, the concentration of $\mathrm{Ca}$ and $\mathrm{P}$ in the SBF does not increase any more. The increase of $\mathrm{Ca}$ and $\mathrm{P}$ concentration 
indicates that $\mathrm{Ca}$ and $\mathrm{P}$ are released from the MAO film into the SBF during the immersion process. Many micropores in the MAO film supply faster channels for the release of $\mathrm{Ca}$ and P. Furthermore, D. Q. Wei et al. ${ }^{16)}$ reported that the release rate of $\mathrm{Ca}$ and $\mathrm{P}$ was decreased by heat treatment applied on the MAO film. This phenomenon may result from the recrystallization of $\mathrm{Ca}$ and $\mathrm{P}$. Generally, the $\mathrm{Ca}$ and $\mathrm{P}$ in amorphous state are easier to release into SBF than that in crystal phase.

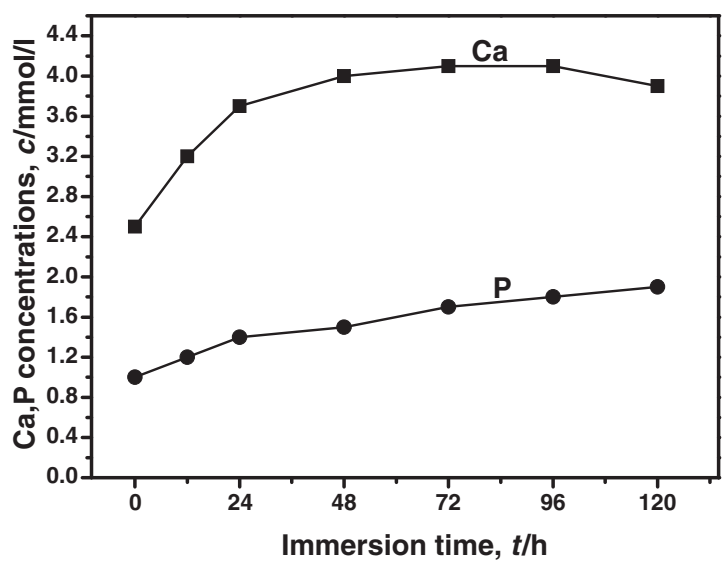

Fig. $5 \mathrm{Ca}$ and $\mathrm{P}$ concentration in the $\mathrm{SBF}$ as a function of MAO coating immersion time.
SEMs of the apatite formed on the MAO coatings prepared at various voltages are presented in Fig. 6. Figure 6 shows that many apatite particles have formed on the MAO films during immersion process. With the increase in voltages applied in the MAO process, the amount of formed apatite increase, even the film prepare at $550 \mathrm{~V}$ is covered by a complete layer of apatite (as presented in Fig. 6(d)). L. Fu et al. ${ }^{14)}$ reported the apatite formation results of the DC MAO film, and these results presented in Fig. 6 show that the apatite formation performance of the AC MAO film superior to the DC mode, and more apatite was formed by the AC MAO film in the same conditions. As presented in 3.2.2, with the increase in voltage the $\mathrm{Ca} \mathrm{P}$ contents increase, which indicates that the effect of voltage on the apatite formation of MAO film may be result from a higher $\mathrm{Ca} \mathrm{P}$ content and release capacity of the MAO film.

In this work, it is suggested that the presence of $\mathrm{Ti}-\mathrm{OH}$ groups on surface is responsible for the MAO coating to form apatite which result in the increase in the degree of supersaturation of the solution with respect to apatite on the surface, and this triggers the apatite nucleation. Additionally, $\mathrm{Ca}$ and $\mathrm{P}$ released from the MAO film also increase the degree of supersaturation, promoting the nucleation and growth of apatite. Moreover, numerous $\mathrm{Ca}$ ions on the surface of the MAO coating may provide good sites for the epitaxial absorption process with respect to apatite ions.
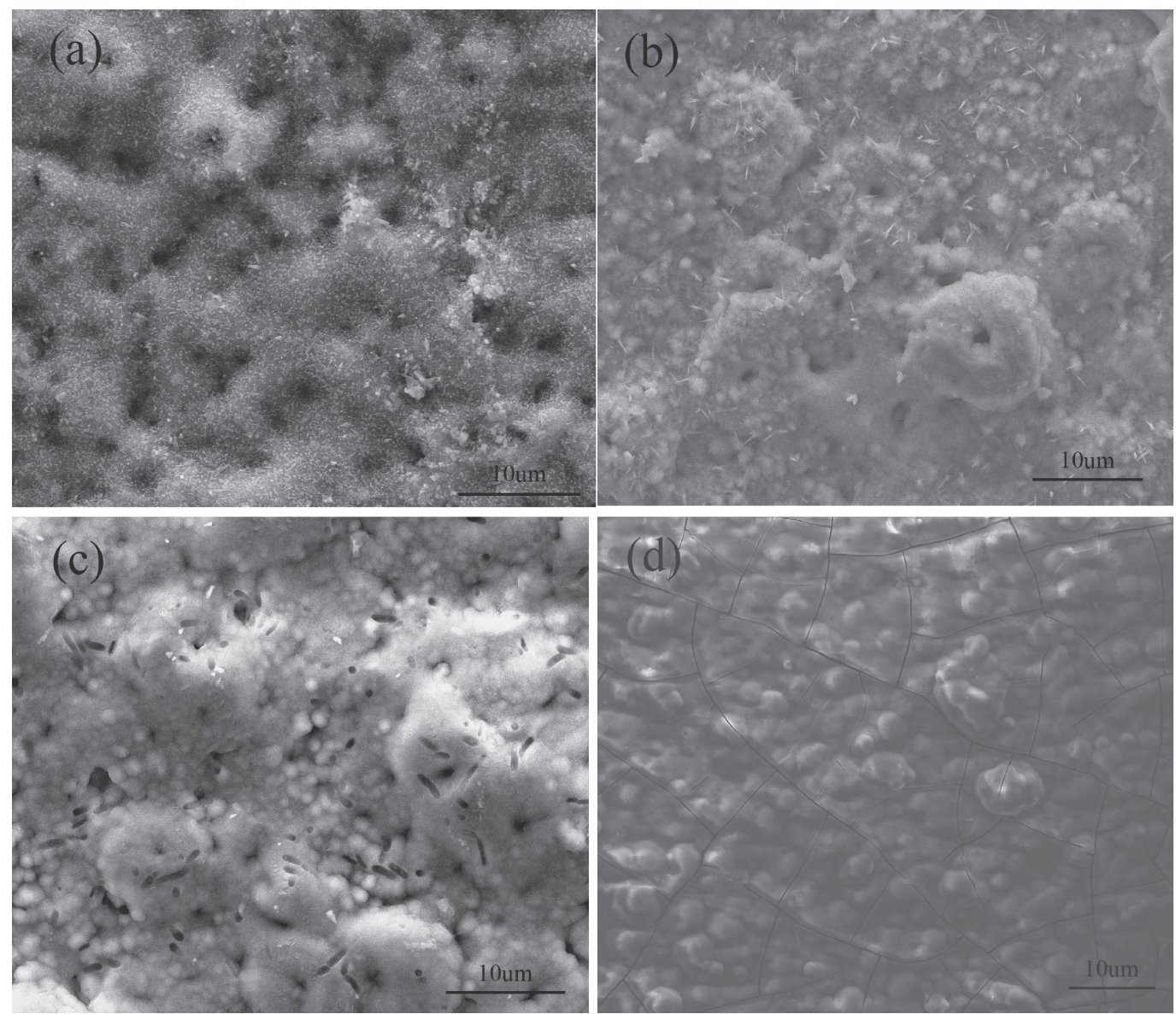

Fig. 6 SEM of the apatite formed on the MAO films prepared at various applied voltages; (a) $300 \mathrm{~V}$, (b) $350 \mathrm{~V}$, (c) $450 \mathrm{~V}$, (d) $550 \mathrm{~V}$. 


\section{Summary}

In this work, MAO was performed on Ti-6Al-4V in an electrolyte containing calcium and phosphate. Various MAO films were prepared on $\mathrm{Ti}-6 \mathrm{Al}-4 \mathrm{~V}$ substrate at the applied voltages from 300 to $550 \mathrm{~V}$ by an $\mathrm{AC}$ power supply. The results show that the MAO films contain amorphous calcium phosphate. The applied voltage has a significant influence on the structure and composition of the MAO film. The MAO film consists of rutile $\mathrm{TiO}_{2}$ and anatase $\mathrm{TiO}_{2}$, and higher voltage is favorable to form rutile phase. With the increase in the applied voltage, the maximum size of micropores tends to increase, and calcium phosphate content and $\mathrm{Ca} / \mathrm{P}$ ratio in the MAO film increase too. The MAO film with the maximum $\mathrm{CaP}$ content and $\mathrm{Ca} / \mathrm{P}$ ratio was prepared $550 \mathrm{~V}$, and $500 \mathrm{~V}$ at ICP-OES results indicate that $\mathrm{Ca}$ and $\mathrm{P}$ are released from the MAO film. The AC MAO mode is more effective to incorporate calcium and phosphorous in the oxide layer than DC mode because higher applied voltages can be applied in it, and the AC MAO films present a better performance in the formation of calcium phosphate which may be result the release of $\mathrm{CaP}$ from $\mathrm{MAO}$ film into SBF.

\section{Acknowledgments}

The authors would like to acknowledge the financial support provided by the Research Fund of Science and Technology Commission of Shanghai Municipality under Grant No. 09ZR1422100, 11441900500, 11441900501 and the Innovation Research Fund of Education of Shanghai Municipality under Grant No. 10YZ94.

\section{REFERENCES}

1) T. Albrektsson, P. I. Brånemark, H.-A. Hasson and J. Lindström: Acta Orthop. Scand. 52 (1981) 155-170.

2) M. Wang: Biomaterials 24 (2003) 2133-2151.

3) I. J. Hwang, K. R. Shin and J. S. Lee: Mater. Trans. 53 (2012) 559-564.

4) D. Q. Wei, Y. Zhou, D. C. Jia and Y. M. Wang: Mater. Chem. Phys. 104 (2007) 177-182.

5) P. Huang, K. W. Xu and Y. Han: J. Porous Mater. 11 (2004) 41-45.

6) J. Takebe, S. Itoh, J. Okada and K. Ishibashi: J. Biomed. Mater. Res. 51 (2000) 398-407.

7) X. L. Zhu, J. L. Ong, S. Y. Kim and K. H. Kim: J. Biomed. Mater. Res. 60 (2002) 333-338.

8) M. Iwasaki, K. Shimada, K. Kudo, Y. Tamagawa and H. Horikawa: Mater. Trans. 52 (2011) 1410-1417.

9) M. Fini, A. Cigada and G. Rondelli: Biomaterials 20 (1999) 15871594.

10) F. C. Ma, P. Liu, W. Li, X. K. Liu and X. H. Chen: Rare Metal Mater. Eng. 41 (2012) 478-480.

11) H. J. Song, K. H. Shin, M. Kook and H. K. Oh: Surf. Coat. Tech. 204 (2010) 2273-2278.

12) Y. Han, S. H. Hong and K. W. Xu: Surf. Coat. Tech. 168 (2003) 249258.

13) X. L. Zhu, K. H. Kim and Y. S. Jeong: Biomaterials 22 (2001) 21992206.

14) L. Fu, Y. Song, F. P. Wang, T. Shimizu, K. Igarashi and L. Zhao: J. Biosci. Bioeng. 100 (2005) 100-104.

15) H. M. Kim, F. Miyaji, T. Kokubo and T. Nakamura: J. Biomed. Mater. Res. 32 (1996) 409-417.

16) D. Q. Wei, Y. Zhou, D. C. Jia and Y. M. Wang: Surf. Coat. Technol. 201 (2007) 8723-8729. 